\title{
Development of Generic Liquid Chromatography-Mass Spectrometry Methods Using Experimental Design
}

\author{
Carmai Seto and Kevin P. Bateman \\ Merck Frosst Canada and Company, Kirkland, Quebec, Canada
}

Berton Gunter

Biometrics Research Department, Merck and Company, Rahway, New Jersey, USA

\begin{abstract}
Standard approaches to development of liquid chromatography-mass spectrometry (LC-MS) methods, either ion-pairing or reversed-phase liquid chromatography, have been through trial and error or intentional variation of experimental factors. These approaches to method optimization fail to take into account interactions between experimental factors and therefore the results may not be optimal for the combination of experimental factors. Another approach to optimization is through the use of chemometrics. Chemometric approaches can be more efficient than trial and error or intentional variation because chemometrics make use of multivariate designs; experimental factors are varied simultaneously at the various levels. Therefore chemometrics can take into account interactions between factors. The goal of this study was to develop a generic ion-pair LC-MS method for the analysis of acidic compounds using a chemometric approach called design of experiments (DOE). Four acidic compounds which cover three classes of acidic functional groups: 1-naphthyl phosphate (1), 1-naphthalenesulfonic acid (2), 2-naphthalenesulfonic acid (3), and (1-naphthoxy)acetic acid (4) were used as model compounds to develop the generic method. This study illustrates that LC-MS conditions can be optimized efficiently with minimal amount of experimentation using a chemometric approach to experimental design. (J Am Soc Mass Spectrom 2002, 13, 2-9) (c) 2002 American Society for Mass Spectrometry
\end{abstract}

\section{$\mathrm{L}$} iquid chromatography-mass spectrometry (LCMS) has become a routine technique in most analytical laboratories, especially in the pharmaceutical industry. Drug discovery today requires high throughput analytical techniques, such as LC-MS and LC-MS-MS [1, 2] for in vitro and in vivo assays for the many chemically diverse compounds being studied. A particular area of interest is the analysis of compounds with only one ionizable group which is acidic. The analysis of acidic compounds using reversed-phase LC often requires the use of nonvolatile buffers or ionpairing (IP) agents [3]. Additives such as tetraalkylammonium salts, phosphates, and sulfuric acid [4-6] have been used to improve retention, peak shape, and to buffer the LC mobile phase. The use of many of these additives have generally been ruled out when liquid chromatography is coupled to a mass spectrometer because of the nonvolatility of the additives, resulting in

Published online November 19, 2001

Address reprint requests to Dr. C. Seto, Merck Frosst Canada \& Company, P.O. Box 1005, Pointe Claire, Quebec H9R 4P8, Canada. E-mail: carmai_seto@merck.com suppression of ionization. However, some nonvolatile salts have been successfully used for IP-LC-MS. Cetyltrimethylammonium chloride has been used for the analysis of $\mathrm{N}$-nitrosoamino acids [7] and low concentrations $(50-500 \mathrm{mM})$ of tetrabutylammonium bromide has been used for the analysis of cyclic nucleotides [8]. A solution to the compatibility issue has been to use more volatile amines, such as dimethylhexylamine, which has been used in the analysis of a metabolite of clodronate [9]. There have been methods developed for the analysis of oligonucleotides and nucleotides by LC-MS using a 1,1,1,3,3,3-hexafluoro-2-isopropanoltriethylamine as the ion-pairing agent $[10,11]$. However, hexafluoroisopropanol is highly corrosive, relatively expensive and must be handled with care.

Standard approaches to development of LC-MS methods, either ion-pairing or reversed-phase liquid chromatography, have either been through trial and error or intentional variation of experimental factors $[12,13]$. The intentional variation approach or the one factor at a time (OFAT) method entails varying one experimental factor with the remaining factors held constant. This method provides an estimate of the effect 
of a particular factor at selected fixed conditions of the other variables. However, for such estimates to be valid, it is necessary to assume that the effect of that single experimental factor is the same over the entire range of the other factors [14]. This method of optimization fails to take into account interactions between experimental factors and therefore the results may not be optimal for the combination of experimental factors. Another approach to optimization is through the use of chemometrics [15]. Chemometric approaches can be more efficient than an OFAT method because they make use of multivariate designs [14]; experimental factors are varied simultaneously at the various levels, which will take into account interactions between factors. With a chemometric approach, a more complete picture of the response(s) is possible.

The goal of this study was to develop a generic ion-pair LC-MS method for the analysis of acidic compounds using a chemometric approach called design of experiments (DOE). Four acidic compounds which cover three classes of acidic functional groups, 1-naphthyl phosphate (1), 1-naphthalenesulfonic acid (2), 2-naphthalenesulfonic acid (3), and (1-naphthoxy)acetic acid (4) were used as model compounds to develop the generic method. Through the optimization of the aqueous LC mobile phase, a generic ion-pairing LC-MS method was developed for the analysis of acidic compounds.

\section{Experimental}

\section{Chemicals}

HPLC grade water was obtained using a Millipore MilliQ system (Bedford, MA). HPLC grade acetonitrile was obtained from EM Science (Gibbstown, NJ). Triethylamine (TEA) and propionic acid were obtained from Anachemia Chemicals (Rouses Point, NY). The naphthalene derivatives studied as well as trifluoroacetic acid and acetic acid were purchased from Aldrich Chemical Company (St. Louis, MO). Formic acid was obtained from BDH Inc. (Toronto, Ontario, Canada).

\section{Instrumentation}

Mass spectral analyses were performed with a Micromass Quattro LC triple quadrupole mass spectrometer (Manchester, UK) equipped with an orthogonal Z-spray electrospray interface. The system was operated in negative ion electrospray mode. MS data were acquired using single ion monitoring (SIM) mode, with a dwell time of $0.3 \mathrm{~s}$ per mass. HPLC separations were performed with a Waters Alliance 2690 Separations Module (Milford, MA). Chromatography was carried out using a Phenomenex $5 \mu \mathrm{m}$ particle, $100 \AA$ pore size Luna C18 reversed-phase column, $50 \mathrm{~mm} \times 4.6 \mathrm{~mm}$ i.d. (Torrance, CA). A linear gradient, from 5 to $45 \%$ organic solvent (acetonitrile) in $10 \mathrm{~min}$, at a flow rate of 1.00 $\mathrm{mL} / \mathrm{min}$ was used, the flow was split using a Valco tee

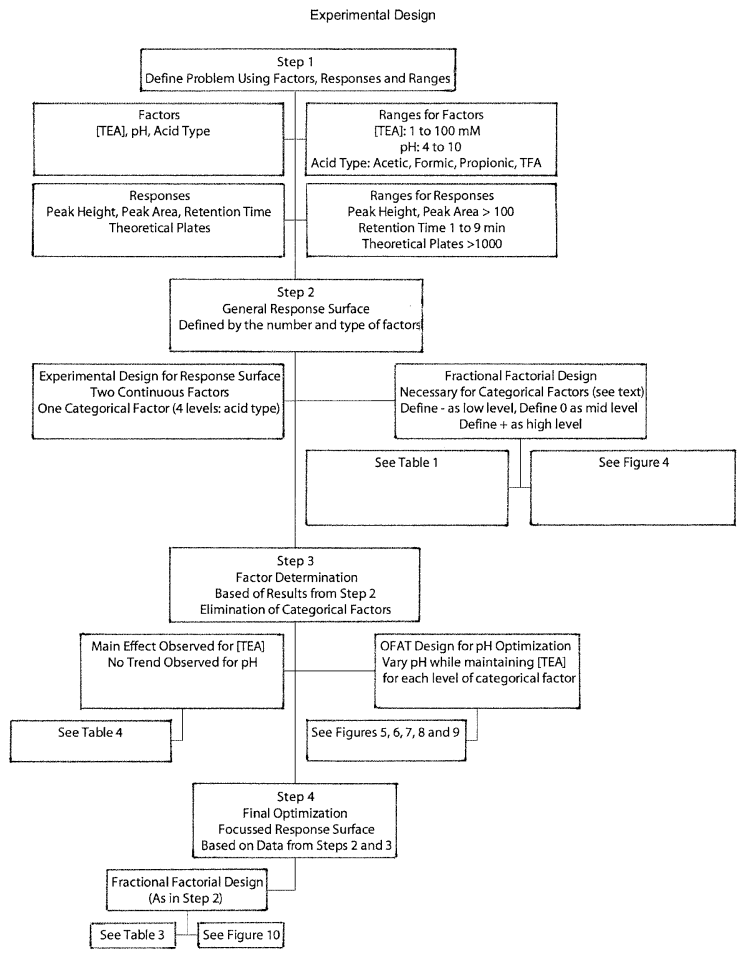

Figure 1. Flow chart summarizing the optimization strategy used to develop generic LC-MS conditions for acidic compounds.

(Houston, TX), with $200 \mu \mathrm{L} / \mathrm{min}$ going to the mass spectrometer. The aqueous mobile phase was prepared by adding acid to aqueous solutions of triethylamine until the desired $\mathrm{pH}$ was reached. The exact composition of the aqueous mobile phase was determined by the experimental design described below.

\section{Experimental Design}

There are several steps required for using the design of experiment approach for optimization, the steps taken to develop the generic LC-MS method is outlined in Figure 1.

\section{Factors}

Three experimental factors chosen for optimization were concentration of ion-pair reagent (Factor A), solution $\mathrm{pH}$ (Factor $\mathrm{B})$, and acid used for $\mathrm{pH}$ adjustment (Factor $\mathrm{C}$ ). Concentration and $\mathrm{pH}$ are continuous factors, which can be varied continuously. Concentration of triethylamine (ion-pair reagent chosen) was varied between 1 and $100 \mathrm{mM}$ and solution $\mathrm{pH}$ was varied between $\mathrm{pH} 4$ and 10. Acid type used for $\mathrm{pH}$ adjustment is a categorical factor, which has discrete levels, such as on or off. Four acids were chosen to adjust the $\mathrm{pH}$, which were formic, acetic, propionic, and trifluoroacetic acids. For each of the acids chosen to adjust $\mathrm{pH}$, a different response surface can be generated for various combinations of $\mathrm{pH}$ and concentration. 


\section{Responses}

Four responses were used to judge the effect of modifying the LC mobile phase on both LC performance and MS response. LC performance was evaluated using the number of theoretical plates and the retention time for each compound. The number of theoretical plates for a gradient elution can be determined using the following equation

$$
N=16\left[(2.3 b+1) G t_{\mathrm{o}} / 2.3 b W\right]^{2}
$$

where $b$ is the gradient steepness parameter, $G$ is the band compression factor, $t_{\mathrm{o}}$ is void time and $W$ is the width of the peak at the baseline. The gradient steepness parameter is defined by

$$
b=t_{\mathrm{o}}(\Delta \Phi) S / t_{\mathrm{G}}
$$

where $\Delta \Phi$ is the change in the percentage of organic solvent from the start to finish of the run and $S$ is an analyte specific parameter and $t_{\mathrm{G}}$ is gradient length time. For all compounds, $S$ was assumed to be 4 because for most low molecular weight compounds ( $<500 \mathrm{Da})$, $S \cong 4$ [3]. The band compression factor is described by

$$
G^{2}=\left[1+p+\left(p^{2} / 3\right)\right] /[1+p]^{2}
$$

where $p=2.3 k_{o} \mathrm{~b} /\left(k_{o}+1\right)$, and $k_{o}=k$ (isocratic) of the analyte under the conditions at the start of the gradient. For all LC aqueous mobile phases, $k_{\mathrm{o}}$ was assumed to be large for each and therefore, $p \cong 2.3 \mathrm{~b}$. Theoretical plates were chosen as a LC response because the greater the number of theoretical plates, the better the peak shape, that is the narrower the peaks. Absolute retention time (RT) was chosen as the second LC response because capacity factor $(k)$ can not be used. For a gradient elution, the effective value of $k\left(k^{*}\right)$ for different compounds will be about the same, unlike for isocratic elutions were each compound has a very different $k$ [3].

Like LC performance, two responses were used to determine MS response; total peak area and peak height. Total peak area or peak height alone are not good measures of MS response because a wide peak and a sharp peak have very different MS sensitivities.

\section{Optimization Strategy}

There were three stages to the optimization once the factors and responses were defined: general survey of the response surfaces, factor determination, and optimization. To survey the experimental factors, a main effects only design was chosen because of the complexity of the system chosen to optimize; two continuous factors, one categorical factor with four levels, four responses for four compounds. However, less information is gained by a main effects design because it assumes that the interactions between experimental
Table 1. Main effects only experiment design

\begin{tabular}{rccc}
\hline Run & Factor $\mathrm{A}^{\mathrm{a}}$ & ${\text { Factor } \mathrm{B}^{\mathrm{b}}}$ & ${\text { Factor } \mathrm{C}^{\mathrm{c}}}^{\mathrm{m}}$ \\
\hline \hline 1 & 0 & 0 & 1 \\
2 & + & - & 2 \\
3 & - & + & 3 \\
4 & 0 & 0 & 2 \\
5 & + & + & 1 \\
6 & + & + & 4 \\
7 & 0 & 0 & 3 \\
8 & + & - & 3 \\
9 & 0 & 0 & 1 \\
10 & - & - & 4 \\
11 & - & + & 2 \\
12 & 0 & 0 & 4 \\
13 & - & - & 1 \\
14 & 0 & 0 & 1 \\
\hline
\end{tabular}

a Factor $\mathrm{A}$ is the concentration of TEA where $-=5 \mathrm{mM}, 0=50 \mathrm{mM}$ $+=100 \mathrm{mM}$. \% ${ }^{\mathrm{b}}$ Factor $\mathrm{B}$ is solution $\mathrm{pH}$ where $-=\mathrm{pH} \mathrm{4,0}=\mathrm{pH} \mathrm{7,+}$ $=\mathrm{pH} 10 . \%^{\mathrm{c}}$ Factor $\mathrm{C}$ is the acid used to adjust $\mathrm{pH}$ where $1=$ acetic acid,

$2=$ formic acid, $3=$ trifluoroacetic acid, $4=$ propionic acid.

factors are not as important as the main effects [13]. An advantage of the main effects design chosen (Table 1) is that it only required 14 runs, including controls. In the main effects design, each run represents a different composition of the aqueous mobile phase. For example, in run 3 in Table 1 , the LC aqueous mobile phase consisted of $5 \mathrm{mM}$ TEA, $\mathrm{pH} 10$ and TFA was used to adjust the $\mathrm{pH}$ of the solution. The main effects design was generated using a modified fractional factorial $2^{(4-1)}$ design, given in Table 2. A design surface is typically generated using a full factorial design, for example with three factors, a $2^{3}$ design is used which takes into account all combinations of the three factors. However, a full factorial design can be fractionated to exclude higher order effects and therefore reduce the number of experiments [16]. This fractionation is possible because of the geometry of a designed experiment. In the general survey, a full factorial or a fractional factorial design was not possible because of the categorical factor with four levels. The $2^{(4-1)}$ design was modified as follows: Factors A and B in Table 1 correspond to Factors A and B in Table 2. The pairing of Factors $\mathrm{D}$ and $\mathrm{E}$ in Table 2 determined the value of Factor C in Table 1. When Factors D and E are both +, Factor $C$ gets the value of 1 . When Factor $D$ is 1 and $E$ is - , Factor $C$ gets the value 2. When Factor $D$ is - and

Table 2. The 4 column, $2^{(4-1)}$ design used to generate the main effects design given in Table 1

\begin{tabular}{ccccc}
\hline Run & Factor A & Factor B & Factor D & Factor E \\
\hline \hline 1 & - & - & - & - \\
2 & + & - & - & + \\
3 & - & + & - & + \\
4 & + & - & - & - \\
5 & - & - & + & + \\
6 & + & + & + & - \\
7 & - & + & + & - \\
8 & + & & & + \\
\hline
\end{tabular}


Table 3. Experimental design used for optimization of LC-MS conditions

\begin{tabular}{ccc}
\hline Run & Factor $^{\mathrm{a}}$ & Factor $^{\mathrm{b}}$ \\
\hline \hline 1 & 0 & - \\
2 & 0 & + \\
3 & + & - \\
4 & + & + \\
5 & 0 & 0 \\
6 & - & - \\
7 & - & + \\
8 & - & 0 \\
9 & + & 0 \\
\hline
\end{tabular}

a Factor $\mathrm{A}$ is the concentration of TEA where $-=1 \mathrm{mM}, 0=10.7 \mathrm{mM}$, $+=22.5 \mathrm{mM} . \%^{\mathrm{b}}$ Factor $\mathrm{B}$ is the solution $\mathrm{pH}$, which is functional group dependent, that is $-=\mathrm{pH} \mathrm{9,0}=\mathrm{pH} \mathrm{9.5,+=} \mathrm{pH} 10$ for 1,2 and 3 and $-=\mathrm{pH} 4,0=\mathrm{pH} 4.8,+=\mathrm{pH} 5.5$ for 4 .

$\mathrm{E}$ is + , Factor $\mathrm{C}$ gets the value 3 , and when Factors D and $E$ are both - , Factor $C$ gets the value of 4 . The modified $2^{(4-1)}$ design was then randomized to remove any experimental bias, and center points were added for each of the values of Factor $C$. Included in the main effects design were 3 replicates, runs 1, 9, and 14 in Table 1, which acted as controls.

Another possible route to survey the response surfaces is to separate the levels of the categorical factor into independent experiments. This would result in four different experimental designs, for example, $\mathrm{pH}$ and concentration of TEA would be varied simultaneously and acetic acid would be used to adjust the $\mathrm{pH}$ for each of the combinations. Therefore, four fractional factorial $2^{(3-1)}$ designs are necessary, which would require a total of 20 runs, 5 runs per design.

Due to the design of the general survey, it was necessary to probe the effect of $\mathrm{pH}$ and acid type using several OFAT experiments. To survey the effects of $\mathrm{pH}$ on MS response and LC performance, the TEA concentration was held constant at $22.5 \mathrm{mM}$, the midpoint of the optimal MS response range, while the $\mathrm{pH}$ was varied from $\mathrm{pH} 4$ to 10 . To address the question of the acid type used to adjust $\mathrm{pH}$, each of the acids was used in separate OFAT experiments. This resulted in three OFAT experiments, each consisting of 5 runs. The information gained from the OFAT experiments eliminated all but one level of the categorical factor as well as narrowing the $\mathrm{pH}$ range for optimization.

For the final optimization of the LC aqueous mobile phase, a modified $2^{(3-1)}$ factorial design with center point (Table 3) was used. The off-corner points were added to the experimental design to cover as much of the surface as possible, enabling the reduction of experimental runs required for optimization. This approach avoids the more time-consuming iterative approach, where a large response surface is optimized into successively smaller response surfaces until the optimal is obtained.

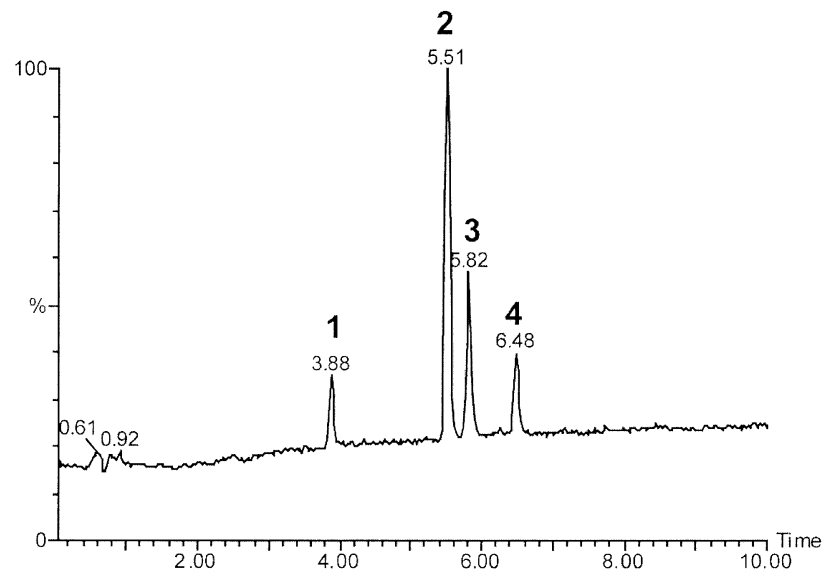

Figure 2. Separation achieved using $50 \mathrm{mM}$ TEA, pH 7.0 using acetic acid to adjust $\mathrm{pH}$ of solution. $\mathbf{1}=1$-naphthylphosphate, $\mathbf{2}=$ 1-naphthalenesulfonic acid, 3 = 2-naphthalenesulfonic acid, and 4 = (1-naphthoxy)acetic acid.

\section{Results and Discussion}

Generic LC-MS conditions were developed using a mixture of the four acidic compounds, and a typical separation achieved using TEA as an ion-pairing agent for 1, 2, 3, and 4 is given in Figure 2. Full scan mass spectra corresponding to the LC-MS data given in Figure 2 is shown in Figure 3. Data acquired for the optimization was collected using SIM.

\section{General Survey of the Response Surfaces}

The main effects design was chosen to survey the response surfaces and to determine if $\mathrm{pH}$ or concentration affected the responses more. A main effect is determined by averaging the effect of changing an individual factor when all other factors are held constant. For example, to determine the effect of concentration on peak area, the peak area when the TEA concentration was high $(100 \mathrm{mM})$ is averaged, regardless of the $\mathrm{pH}$ or acid used, which can be denoted as Factor $\mathrm{A}^{+}$. The peak area when the TEA concentration was low $(5 \mathrm{mM})$ is also averaged regardless of $\mathrm{pH}$ or acid used, which can be denoted as Factor $\mathrm{A}^{-}$. The effect of TEA concentration on peak area can be determined by eq 4 :

$$
\text { Factor } \mathrm{A}_{\text {effect }}=\text { Factor } \mathrm{A}^{+}-\text {Factor } \mathrm{A}^{-}
$$

Similar calculations are performed to determine the effect of solution $\mathrm{pH}$ (Factor B) on peak area. This is possible because there is a general symmetry in the experimental design. The main effect, that is, if solution $\mathrm{pH}$ had a greater effect on peak area than concentration, is determined by the following

$$
\text { Main effect }=\text { Factor } A_{\text {effect }}-\text { Factor } B_{\text {effect }}
$$

If concentration has a greater effect on peak area, the 

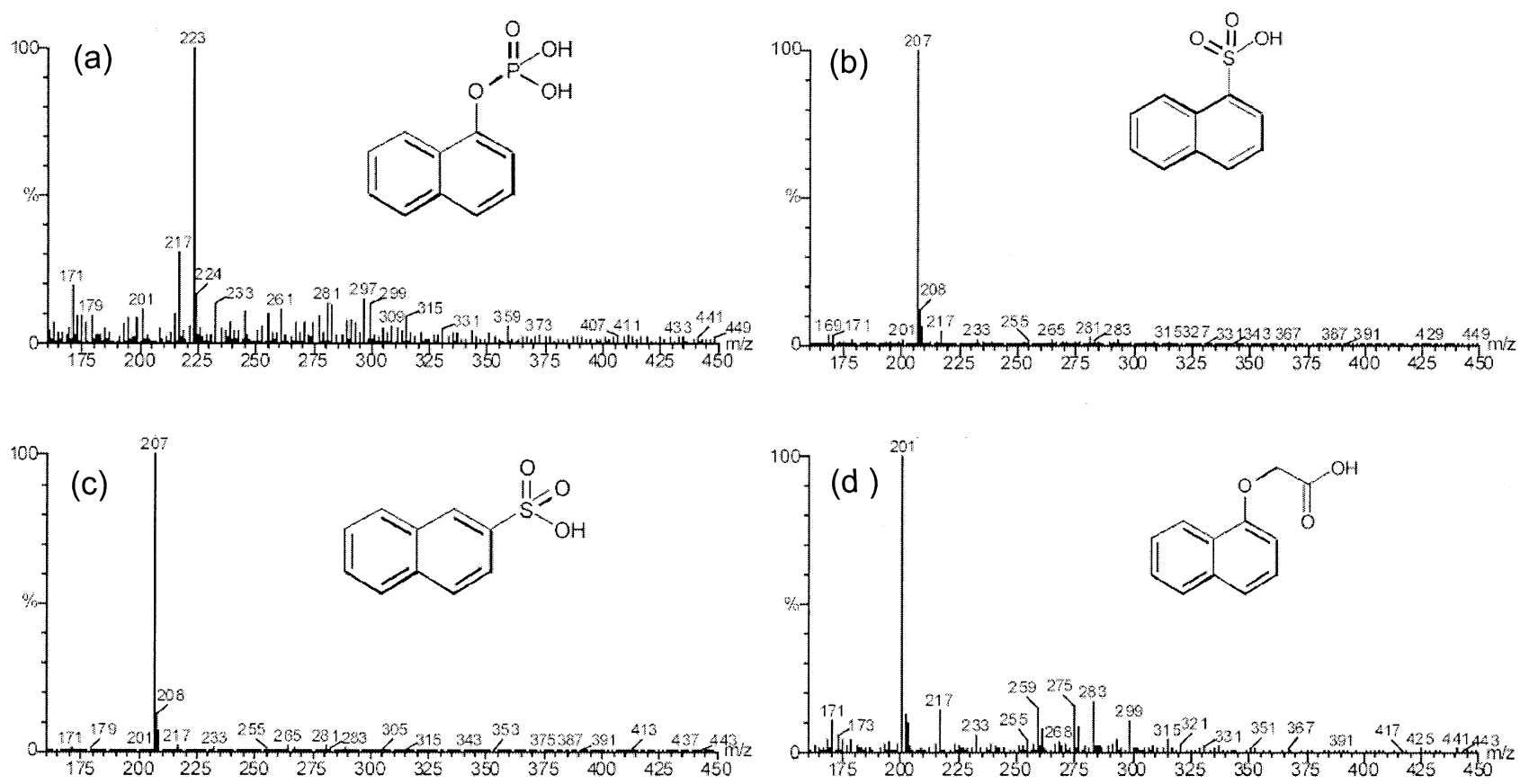

Figure 3. Full scan mass spectral data for (a) 1-naphthylphosphate, (b) 1-naphthalenesulfonic acid,

(c) 2-naphthalenesulfonic acid, and (d) (1-naphthoxy)acetic acid.

result from eq 5 would have a positive value. If $\mathrm{pH}$ has a greater effect on peak area, the result from eq 5 would have a negative value.

The main effects for all responses are summarized for each compound in Table 4. Concentration of ionpairing reagent has the greater effect on MS response (peak height and peak area) than $\mathrm{pH}$ for all compounds. The change in peak height going from 100 to 5 mM TEA is greater than the change in peak height going from $\mathrm{pH}$ 10 to 4 , therefore concentration has the greater effect on peak height than $\mathrm{pH}$. Concentration of TEA and $\mathrm{pH}$ did not seem to affect the LC performance (number of theoretical plates and retention time), except for $\mathbf{4}$, where $\mathrm{pH}$ has an effect on the number of theoretical plates.

Along with determining main effects, the main effects experimental design also provides insight into the response surfaces. Figure 4 illustrates the peak height response surface for 3 . The greatest MS response occurred at a lower concentration of TEA $(5 \mathrm{mM})$. The worst MS response occurred at a higher concentration of TEA (100 mM). Table 5 summarizes the greatest and worst LC performance and MS response for each com-

Table 4. Main effects for each compound categorized by response

\begin{tabular}{cccccc}
\hline & \multicolumn{2}{c}{ LC performance } & & \multicolumn{2}{c}{ MS response } \\
\cline { 2 - 2 } Compound & RT & $N$ & & Area & Height \\
\hline \hline 1 & No effect & No effect & concentration concentration \\
2 & No effect & No effect & concentration concentration \\
3 & No effect & No effect & concentration concentration \\
4 & No effect & pH & concentration concentration \\
\hline
\end{tabular}

pound. To determine the greatest/worst performance and response, several compromises were made. For the best LC performance, a compromise between the number of theoretical plates and retention time was used; retention time was sacrificed for a greater number of theoretical plates. For best MS response, peak area was sacrificed for a greater peak height.

From the response surfaces, it was evident that TFA

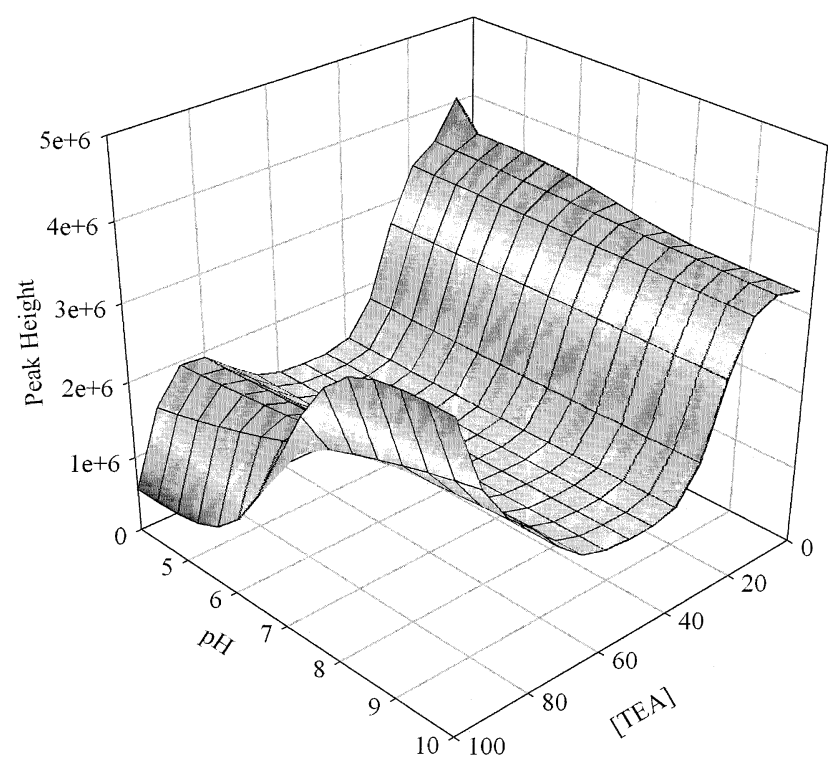

Figure 4. Peak height response surface for 3 . The concentration of triethylamine was varied between 5 and $100 \mathrm{mM}, \mathrm{pH}$ was varied between 4 and 10 and four different acids were used to adjust the $\mathrm{pH}$. The greatest response occurred at low concentration of TEA. 
Table 5. Summary of the best and worst LC performance and MS response according to compound

\begin{tabular}{|c|c|c|c|c|}
\hline \multirow[b]{2}{*}{ Compound } & \multicolumn{2}{|c|}{ LC performance } & \multicolumn{2}{|c|}{ MS response } \\
\hline & Best performance & Worst performance & Best response & Worst response \\
\hline 1 & $\begin{array}{l}100 \text { mM TEA, pH } 4 \\
\text { (formic acid) }\end{array}$ & $\begin{array}{l}100 \mathrm{mM} \text { TEA, } \mathrm{pH} 4 \\
\quad \text { (trifluoroacetic acid) }\end{array}$ & $\begin{array}{l}5 \text { mM TEA, pH } 10 \\
\text { (formic acid) }\end{array}$ & $\begin{array}{l}100 \mathrm{mM} \text { TEA, pH } 5 \\
\text { (formic acid) }\end{array}$ \\
\hline 2 & $\begin{array}{l}50 \text { mM TEA, } \mathrm{pH} 7 \\
\quad \text { (trifluoroacetic acid) }\end{array}$ & $\begin{array}{l}5 \text { mM TEA, pH } 4 \\
\text { (acetic acid) }\end{array}$ & $\begin{array}{c}5 \text { mM TEA, pH } 4 \\
\text { (acetic acid) }\end{array}$ & $\begin{array}{l}100 \mathrm{mM} \text { TEA, } \mathrm{pH} 4 \\
\text { (trifluoroacetic acid) }\end{array}$ \\
\hline 3 & $\begin{array}{l}50 \text { mM TEA, pH } 7 \\
\text { (trifluoroacetic acid) }\end{array}$ & $\begin{array}{l}50 \text { mM TEA, pH } 7 \\
\text { (acetic acid) }\end{array}$ & $\begin{array}{l}5 \text { mM TEA, pH } 10 \\
\text { (formic acid) }\end{array}$ & $\begin{array}{l}100 \mathrm{mM} \text { TEA, } \mathrm{pH} 4 \\
\text { (trifluoroacetic acid) }\end{array}$ \\
\hline 4 & $\begin{array}{l}50 \text { mM TEA, pH } 7 \\
\text { (acetic acid) }\end{array}$ & $\begin{array}{l}100 \mathrm{mM} \text { TEA, pH } 4 \\
\text { (trifluoroacetic acid) }\end{array}$ & $\begin{array}{l}50 \text { mM TEA, pH } 7 \\
\text { (acetic acid) }\end{array}$ & $\begin{array}{l}100 \mathrm{mM} \text { TEA, } \mathrm{pH} 4 \\
\text { (trifluoroacetic acid) }\end{array}$ \\
\hline
\end{tabular}

should not be used to adjust $\mathrm{pH}$ because TFA gave the majority of the worst MS response and LC performance (see Figure 4 and Table 5). In order to optimize MS response, lower concentrations of TEA must be used. As for optimal $\mathrm{pH}$ for MS response, there is no general trend observed. There was a general trend for optimal LC performance, the concentration of TEA ranging from 5 to $100 \mathrm{mM}$.

The effect of LC modifiers on MS response was also determined using the main effects design. The MS parameters, cone voltage and capillary voltage, were optimized for each compound at the various mobile phase conditions which are described in Table 1, excluding those containing TFA. Regardless of LC mobile phase composition, the MS response for $\mathbf{1}$ and 4 increased with optimization of the MS parameters, and the MS response for $\mathbf{2}$ and $\mathbf{3}$ did not vary greatly with optimization of the MS parameters. These results indicate that optimization of the MS parameters is neutral with respect to the LC modifiers, even at high concentrations of TEA. In other words, the gain in sensitivity obtained by tuning at each mobile phase condition is minimal.

\section{Factor Determination}

A great deal of information about the response surfaces was obtained from the main effects experiment, such as

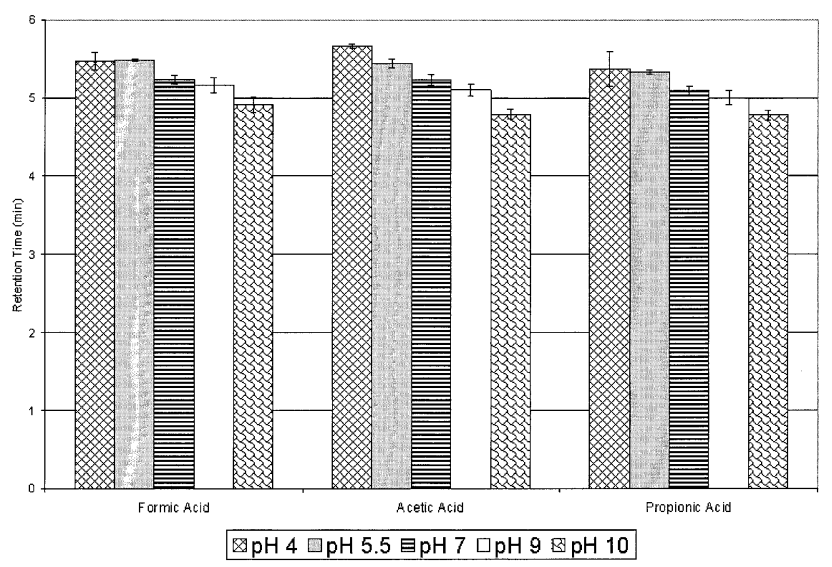

Figure 5. Effect of type of acid to adjust $\mathrm{pH}$ on absolute retention time of 2. Concentration of triethylamine held constant at 22.5 $\mathrm{mM}, \mathrm{pH}$ varied between 4 and 10 .
TFA should not be used to adjust $\mathrm{pH}$, concentration is the most important factor for MS response, and lower concentrations of TEA are needed for optimal MS response. However, there still remain two obstacles to optimization, the three remaining levels of the categorical factor and the optimal $\mathrm{pH}$ range. Therefore, three OFAT experiments were employed to address the issues of $\mathrm{pH}$ and the level of the categorical factor, described bove.

LC performance for Compound $\mathbf{1}$ followed distinct trends; the number of theoretical plates increased with increasing $\mathrm{pH}$ and the retention time for $\mathbf{1}$ decreased with increasing $\mathrm{pH}$.

Unlike Compound 1, the type of acid chosen to adjust the $\mathrm{pH}$ of the solution also had an effect on the number of theoretical plates for Compounds 2 and 3. The number of theoretical plates did not very greatly over the $\mathrm{pH}$ when propionic acid and acetic acid were used to adjust $\mathrm{pH}$. However, with acetic acid there was a marked decrease in the number of theoretical plates at $\mathrm{pH}$ 5.5. When formic acid was used to adjust the $\mathrm{pH}$, the number of theoretical plates decreased with increasing $\mathrm{pH}$. The retention time for Compounds 2 and 3 decreased with increasing $\mathrm{pH}$.

For Compound 4, the number of theoretical plates decreased with increasing $\mathrm{pH}$ when propionic acid was used, increased with increasing $\mathrm{pH}$ when formic acid

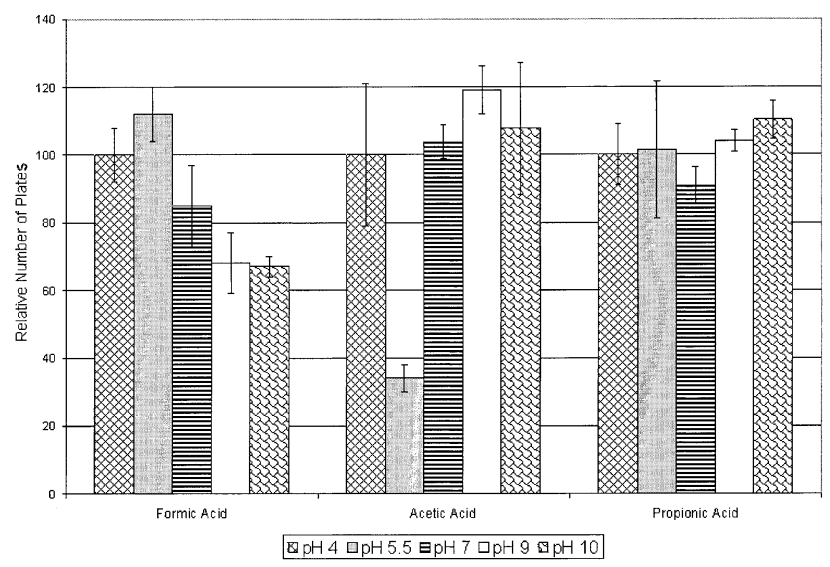

Figure 6. Effect of type of acid to adjust $\mathrm{pH}$ on number of theoretical plates of $\mathbf{2}$. Concentration of triethylamine held constant at $22.5 \mathrm{mM}$ and $\mathrm{pH}$ varied between 4 and 10 . 


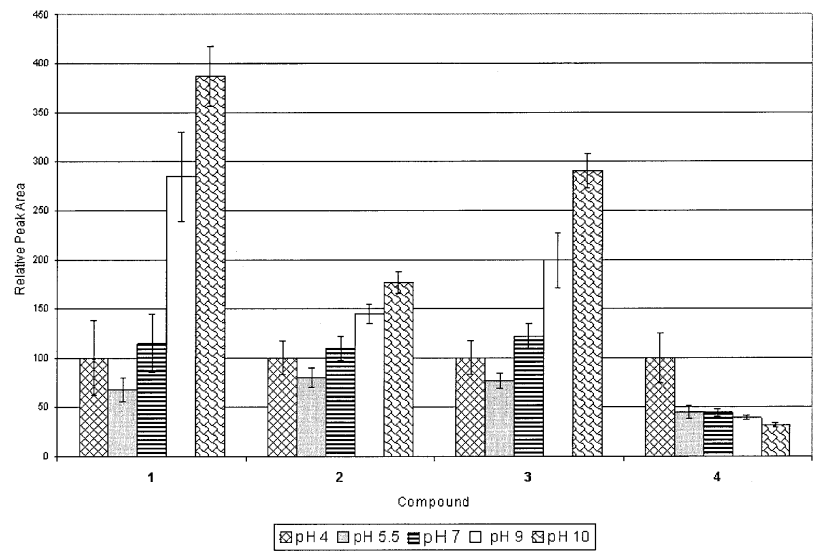

Figure 7. Effect of $\mathrm{pH}$ on peak area of 1, 2, 3, and 4. Triethylamine concentration was held constant at $22.5 \mathrm{mM}$, formic acid was used to adjust $\mathrm{pH}$ and $\mathrm{pH}$ was varied between 4 and 10 .

was used and did not vary greatly as $\mathrm{pH}$ increased when acetic acid was used. The effect of $\mathrm{pH}$ and acid is illustrated in Figures 5 and 6 for 2. As for the other compounds, the retention time for Compound 4 decreased with increasing $\mathrm{pH}$.

For Compounds 1, 2, and 3 the MS response increased with increasing $\mathrm{pH}$, with a maximum response occurring around $\mathrm{pH} 10$ (Figures 7 and 8). However, for 4, MS response decreased with increasing $\mathrm{pH}$, with a maximum response occurring around $\mathrm{pH} 4$ (Figures 7 and 8). In all cases, MS response was more dependent on $\mathrm{pH}$ than on the acid used to adjust $\mathrm{pH}$. Since MS response was considered the more important of the two responses, the $\mathrm{pH}$ ranges chosen for optimization were between $\mathrm{pH} 4$ and 5.5 for 4 and between $\mathrm{pH} 9$ and 10 for 1,2 , and 3.

To determine which acid was best to adjust $\mathrm{pH}$, the MS responses of each compound were compared at their optimal $\mathrm{pH}$; for $\mathbf{1}, \mathbf{2}$, and 3 the responses were compared at $\mathrm{pH} 10$, while the responses for 4 were compared at $\mathrm{pH} 4$. Propionic acid gave the greatest MS response followed by formic acid and acetic acid, as

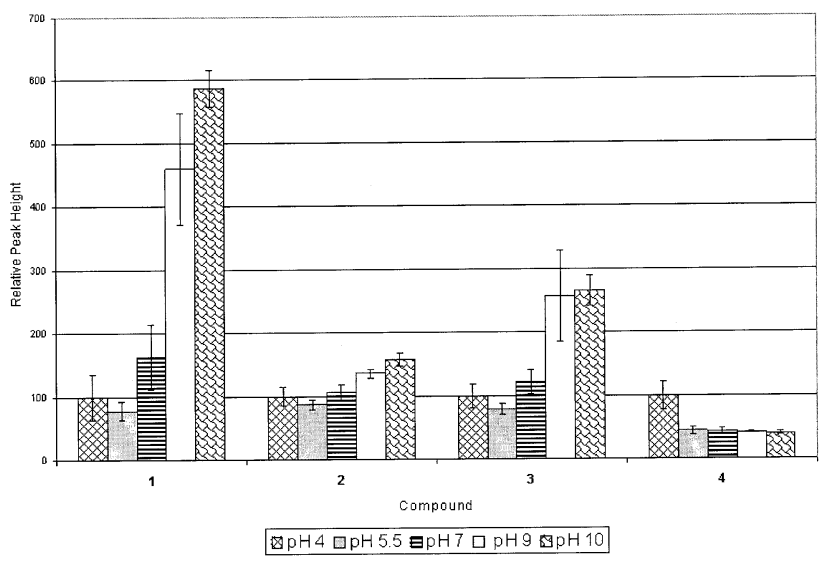

Figure 8. Effect of $\mathrm{pH}$ on peak height of 1, 2, 3, and 4. Triethylamine concentration was held constant at $22.5 \mathrm{mM}$, formic acid was used to adjust $\mathrm{pH}$ and $\mathrm{pH}$ varied between 4 and 10 .

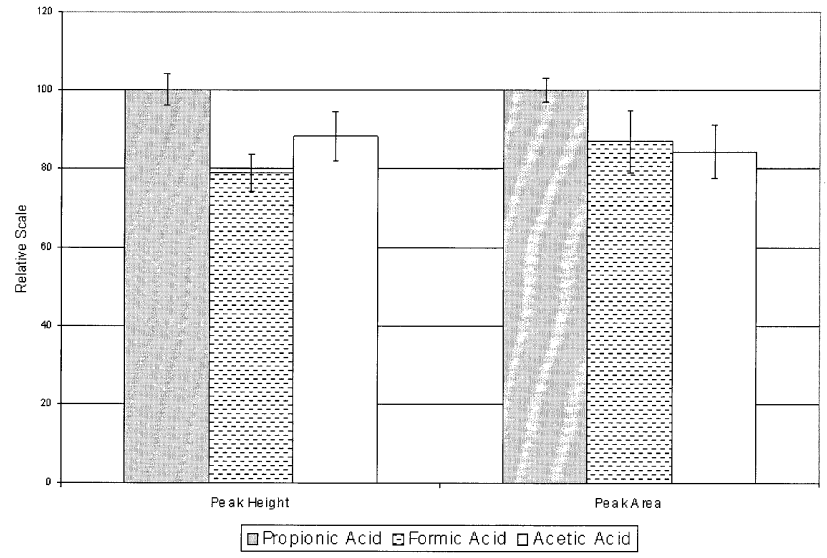

Figure 9. The effect of acid used to for $\mathrm{pH}$ adjustment of the MS response (peak height and peak area) of $\mathbf{1}$. Concentration of triethylamine held constant at $22.5 \mathrm{mM}, \mathrm{pH}$ held constant at 10 and adjust type used to adjust $\mathrm{pH}$ was varied.

illustrated in Figure 9 for 1. There was on average 37\% increase in peak height and a 19\% increase in peak area by switching from acetic acid to propionic acid to adjust the $\mathrm{pH}$.

\section{Optimization of LC-MS Conditions}

From the main effects design, the optimal concentration range for TEA was determined along with the elimination of one level of the categorical factor. From the OFAT experiments, the optimal $\mathrm{pH}$ ranges as well as which acid used to adjust $\mathrm{pH}$ would give optimal MS response (propionic acid) were determined. LC-MS conditions were optimized for 1, 2, and 3 between 1-22.5 mM TEA, $\mathrm{pH} 9-10$ and using propionic acid to adjust $\mathrm{pH}$. LC-MS conditions were also optimized for 4 , but between 1-22.5 mM TEA, $\mathrm{pH} 4-5.5$ and using propionic acid to adjust $\mathrm{pH}$.

Both the optimal MS response and LC performance for 4 occurred between 1-10 mM TEA and $\mathrm{pH} 4-4.8$ (not shown). The results indicate that carboxylic acid containing compounds should not be analyzed using ion-pairing liquid chromatography; instead, reversephase liquid chromatography using acidic mobile phases is appropriate, as demonstrated previously $[12,17]$.

The optimal MS responses for 1, 2, and 3 occurred between 1-10 mM TEA and $\mathrm{pH}$ 9.5-10, while the retention of the compounds occurred between 11-22.5 $\mathrm{mM}$ TEA and $\mathrm{pH} 9-9.5$, and the greatest number of theoretical plates occurred between 1-10 mM TEA and $\mathrm{pH}$ 9.5-10. Figure 10 illustrates the response surfaces for 1. Optimal MS response occurred around $1 \mathrm{mM}$ TEA, however $\mathbf{1}$ is not retained on column. At higher concentrations, between 11-22.5 mM TEA, the $\mathbf{1}$ is retained the most, however MS response has decreased compared to the response between 1-11 mM TEA. The ideal conditions for a generic method, compromising both LC performance and MS response are between 11-22.5 mM TEA, between $\mathrm{pH}$ 9.5-10. The generic LC-MS conditions 


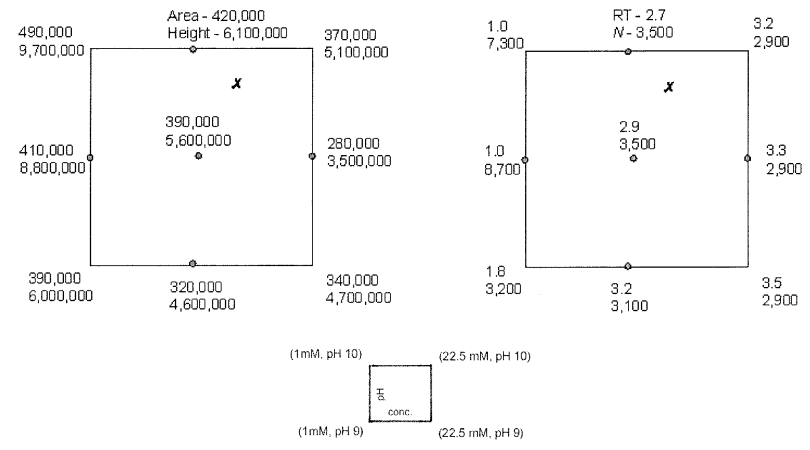

Figure 10. Response surfaces for $\mathbf{1}$ after final optimization. $\mathrm{pH}$ is represented on the vertical axis and concentration of triethylamine on the horizontal axis. The chart on the left represents MS response while the chart on the right represents LC performance. Top left corner represents the LC mobile phase of $1 \mathrm{mM}$ TEApropionic acid, $\mathrm{pH} 10$. The center point represents the LC mobile phase of $10.8 \mathrm{mM}$ TEA-propionic acid, $\mathrm{pH}$ 9.5. The bottom right corner represents the LC mobile phase of $22.5 \mathrm{mM}$ TEA-propionic acid, $\mathrm{pH}$ 9. The $\mathrm{X}$ represents the generic LC conditions developed, $12.5 \mathrm{mM}$ TEA-propionic acid, $\mathrm{pH}$ 9.8, for the analysis of acidic compounds excluding carboxylic acids.

developed for use in the laboratory contain $12.5 \mathrm{mM}$ TEA, pH 9.8 using propionic acid to adjust the $\mathrm{pH}$.

\section{Conclusions}

A generic ion-pairing liquid chromatography method has been developed for the analysis of acidic compounds, excluding compounds containing carboxylic acid functional groups, using a chemometric approach. Optimal generic conditions contain between 11 and 22.5 mM TEA, between $\mathrm{pH} 9.5$ and 10, and propionic acid was used to adjust the $\mathrm{pH}$. The generic method used in the laboratory contains $12.5 \mathrm{mM}$ TEA, $\mathrm{pH} 9.8$ using propionic acid to adjust the $\mathrm{pH}$. Several steps were required to determine these generic conditions (Figure 1). A main effects only design was first used to survey a large area of the response surfaces. Then several OFAT experiments were used to narrow the experimental ranges for optimization. Optimization was then finally achieved using a modified factorial design. This study illustrates that LC-MS conditions can be optimized efficiently with minimal amount of experimentation using a chemometric approach to experimental design.

\section{References}

1. Watt, A. P.; Morrison, D.; Evans, D. C. Approaches to HigherThroughput Pharmacokinetics (HTPK) in Drug Discovery. Drug Discovery Today 2000, 5, 17-24.

2. Romanyshyn, L.; Tiller, P. R.; Hop, C. E. C. A. Bioanalytical Applications of Fast Chromatography to High-Throughput Liquid Chromatography/Tandem Mass Spectrometric Quantitation. Rapid Commun. Mass Spectrom. 2000, 14, 1662-1668.
3. Snyder, L. R.; Kirkland, J. J.; Glajch, J. L.; 2nd John Wiley \& Sons, Inc: New York, 1997.

4. Tavazzi, B.; Vagnozzi, R.; Di Pierro, D.; Amorini, A. M.; Fazzina, G.; Signoretti, S.; Marmarou, A.; Caruso, I.; Lazzarino, G. Ion-Pairing High-Performance Liquid Chromatographic Method for the Detection of $\mathrm{N}$-Acetylaspartate and N-Acetylglutamate in Cerebral Tissue Extracts. Anal. Biochem. 2000, 277, 104-108.

5. Uesugi, T.; Sano, K.; Uesawa, Y.; Ikegami, Y.; Mohri, K. Ion-Pair Reversed-Phase High-Performance Liquid Chromatography of Adenine Nucleotides Using Triethylamine as a Couterion. J. Chromatogr. B 1997, 703, 63-74.

6. Qiu, J. Statistics Aided Optimization for High-Performance Liquid Chromatographic Analysis of Organic Acids in Tobacco. J. Chromatogr. A 1999, 859, 153-158.

7. Cheng, C. F.; Tsang, C. W. Separation of N-Nitrosoamino Acids by $\mathrm{C} 18$ Reversed-Phase Ion-Pair High-Performance Liquid Chromatography and Compatible Detection by Electrospray Ionization Mass Spectrometry. J. Chromatogr. A 1999, 849, 389-402.

8. Witters, E.; Van Dongen, W.; Esmans, E. L.; Van Onckelen, H. A. Ion-Pair Liquid Chromatography-Electrospray Mass Spectrometry for the Analysis of Cyclic Nucleotides. J. Chromatogr. B 1997, 694, 55.

9. Mönkkönen, H.; Moilanen, P.; Mönkkönen, J.; Frith, J. C.; Rogers, M. J.; Auriola, S. Analysis of an Adenine NucleotideContaining Metabolite of Clodronate Using Ion Pair HighPerformance Liquid Chromaography-Electrospray Ionisation Mass Spectrometry. J. Chromatogr. B 2000, 738, 395-403.

10. Apffel, A.; Chakel, J. A.; Fischer, S.; Lichtenwalter, K.; Hancock, W. S. New Procedure for the Use of High-Performance Liquid Chromatography-Electrospray Ionization Mass Spectrometry for the Analysis of Nucleotides and Oligonucleotides. J. Chromatogr. A 1997, 777, 3-21.

11. Apffel, A.; Chakel, J. A.; Fischer, S.; Lichtenwalter, K.; Hancock, W. S. Analysis of Oligonucleotides by HPLC-Electrospray Ionization Mass Spectrometry. Anal. Chem. 1997, 69, $1320-1325$.

12. Jemal, M.; Almond, R; Ouyang, Z.; Teitz, D. Negative Ion Electrospray High-Performance Liquid ChromatographyMass Spectrometry Method Development of a Highly Polar Phosphonic Acid/Sulfonic Acid Compound in Plasma. Optimization of Ammonium Acetate Concentration and In-Source Collision-Induced Dissociation. J. Chromatogr. B 1997, 703, 167-175.

13. Køppen, B.; Spliid, N. H. Determination of Acidic Herbicides Using Liquid Chromatography with Pneumatically Assisted Electrospray Ionization Mass Spectrometric and Tandem Mass Spectrometric Detection. J. Chromatogr. A 1998, 803, 157-168.

14. Box, G. E. P.; Hunter, W. G.; Hunter, J. S. Statistics for Experimenters: An Introduction to Design, Data Analysis and Model Building. John Wiley \& Sons, Inc: New York, 1978, pp 306-313.

15. Siouffi, A. M.; Phan-Tan-Luu, R. Optimization Methods in Chromatography and Capillary Electrophoresis. J. Chromatogr. A 2000, 892, 75-106.

16. Ragonese, R.; Mulholland, M.; Kalman, J. Full and Fractionated Experimental Designs for Robustness Testing in the High-Performance Liquid Chromatographic Analysis of Codeine Phosphatem Pseudoephedrine Hydrochloride and Chlorpheniramine Maleate in a Pharmaceutical Preparation. J. Chromatogr. A 2000, 870, 45-51.

17. Waksmundzka-Hajnos, M. Chromatographic Separations of Aromatic Carboxylic Acids. J. Chromatogr. B 1998, 717, 93-118. 